\title{
Perspective
}

\section{Considerations from the IQ Induction Working Group in Response to Drug-Drug Interaction Guidance from Regulatory Agencies: Focus on Downregulation, CYP2C Induction, and CYP2B6 Positive Control ${ }^{[\mathrm{S}}$}

\author{
Niresh Hariparsad, Diane Ramsden, Jairam Palamanda, Joshua G. Dekeyser, Odette A. Fahmi, \\ Jane R. Kenny, Heidi Einolf, Michael Mohutsky, Magalie Pardon, Y. Amy Siu, Liangfu Chen, \\ Michael Sinz, Barry Jones, Robert Walsky, Shannon Dallas, Suresh K. Balani, George Zhang, \\ David Buckley, and Donald Tweedie
}

Vertex Pharmaceuticals, Boston, Massachusetts (N.H.); Genentech, South San Francisco, California (J.R.K.); Novartis Pharmaceuticals, Florham Park, New Jersey (H.E.); Eli Lilly and Company, Indianapolis, Indiana (M.M.); Boehringer Ingelheim, Ridgefield, Connecticut (D.R.); Merck and Co., Kenilworth, New Jersey (J.P.), Amgen Inc., Thousand Oaks, California (J.D.), Pfizer Global Research and Development, Groton, Connecticut (O.A.F.); Sanofi Pharmaceuticals, ChillyMazarin, France

(M.P.); Eisai Pharmaceuticals, Andover, Massachusetts (A.Y.S.); Glaxo SmithKline, King of Prussia, Pennsylvania (L.C.); Bristol-Myers Squibb, Wallingford, Connecticut (M.S.); AstraZeneca, Mölndal, Sweden (B.J.); EMD Serono, Billerica, Massachusetts (R.W.);Janssen R\&D, Spring House, Pennsylvania (S.D.); Millennium Pharmaceuticals, Inc., a wholly owned subsidiary of Takeda Pharmaceuticals Co., Cambridge, Massachusetts (S.K.B.); Corning Life Sciences; Woburn, Massachusetts (G.Z.); XenoTech LLC, Lenexa, Kansas (D.B.); Merck and Co., West Point, Pennsylvania (D.T.)

Received December 8, 2017; accepted June 16, 2017

\begin{abstract}
The European Medicines Agency (EMA), the Pharmaceutical and Medical Devices Agency (PMDA), and the Food and Drug Administration (FDA) have issued guidelines for the conduct of drug-drug interaction studies. To examine the applicability of these regulatory recommendations specifically for induction, a group of scientists, under the auspices of the Drug Metabolism Leadership Group of the Innovation and Quality (IQ) Consortium, formed the Induction Working Group (IWG). A team of 19 scientists, from 16 of the 39 pharmaceutical companies that are members of the IQ Consortium and two Contract Research Organizations reviewed the recommendations, focusing initially on the current EMA guidelines. Questions were collated from IQ member companies as to which aspects of the guidelines require further evaluation. The EMA was then approached to provide insights
\end{abstract}

into their recommendations on the following: 1) evaluation of downregulation, 2) in vitro assessment of CYP2C induction, 3) the use of CITCO as the positive control for CYP2B6 induction by CAR, 4) data interpretation (a 2-fold increase in mRNA as evidence of induction), and 5) the duration of incubation of hepatocytes with test article. The IWG conducted an anonymous survey among IQ member companies to query current practices, focusing specifically on the aforementioned key points. Responses were received from 19 companies. All data and information were blinded before being shared with the IWG. The results of the survey are presented, together with consensus recommendations on downregulation, CYP2C induction, and CYP2B6 positive control. Results and recommendations related to data interpretation and induction time course will be reported in subsequent articles.

\section{Introduction}

Enzyme induction can lead to decreased systemic exposure of the inducing drug (autoinduction) or of a coadministered drug that is metabolized by the induced enzyme and can result in increased formation of active or toxic metabolites that change the pharmacologic

https://doi.org/10.1124/dmd.116.07457

$\$$ This article has supplemental material available at DMD.aspetjournals.org. and toxicologic outcomes in the induced state compared with the noninduced state (Guengerich et al., 1990; Lin, 2006). Since hepatocytes contain the full complement of transcription factors, metabolic enzymes, and transporters, as well as coactivators and corepressors, isolated hepatocytes are now recognized as the most relevant and practical in vitro model for induction studies (Hewitt et al., 2007a,c; Godoy et al., 2013). Therefore, the use of plated human hepatocytes is considered the "gold standard" in vitro assay for induction-risk assessment.

ABBREVIATIONS: AhR, aryl hydrocarbon receptor; AUC, area under the curve; CITCO, 6-(4-chlorophenyl)imidazo[2,1-b] [1,3]thiazole-5carbaldehyde O-3,4-dichlorobenzyl) oxime; CAR, constitutive androstane receptor; CRO, Contract Research Organization; DDI, drug-drug interaction; DME, drug-metabolizing enzymes; EMA, European Medicines Agency; FDA, Food and Drug Administration; GR, glucocorticoid receptor; IQ, Innovation and Quality Consortium; IVIVE, in vitro to in vivo extrapolation; IWG, induction Working Group; MRP, multidrug resistance protein; NCE, new chemical entity; P450, cytochrome P450; PB, phenobarbital; PMDA, Pharmaceutical and Medical Devices Agency; PXR, pregnane-X receptor; TDI, time-dependent inhibition. 
Given the common goal of regulatory authorities and industry sponsors to be able to predict the occurrence and extent of induction in humans from preclinical studies, the Pharmaceutical Research and Manufacturers of America published a white paper with the intent of suggesting best practices for in vitro and in vivo pharmacokinetic DDI studies (Bjornsson et al., 2003). This paper was followed up with an additional white paper in which the Pharmaceutical Innovation Steering Committee, under the auspices of Pharmaceutical Research and Manufacturers of America, conducted a survey to understand the predictability of various in vitro experimental models for cytochrome 450 (P450) induction that was used across the industry (Chu et al., 2009). Since the publication of this white paper and survey, the FDA, EMA, and the PMDA have issued updated guidelines: DDI Draft Guidance for Industry (http://www.fda.gov/downloads/drugs/guidancecomplianceregulatoryinformation/guidances/ucm292362.pdf), Guideline on the Investigation of Drug Interactions (http://www.ema.europa.eu/ docs/en_GB/document_library/Scientific_guideline/2012/07/WC500129606. pdf), and the Drug Interaction Guideline for Drug Development and Labeling Recommendations (MHLW, 2014).

The current EMA and PMDA (MHLW, 2014) DDI guidelines specifically mention the potential for the in vitro induction studies to detect enzyme downregulation and, if the effect of the new chemical entity (NCE) is concentration-dependent, recommend additional in vitro or in vivo studies to further investigate (MHLW, 2014), the key question being what constitutes a significant level of decrease in mRNA and protein in vitro and whether this translate to in vivo. Similarly, the EMA guidelines also recommend that pharmaceutical companies generate in vitro human hepatocyte CYP2C induction data if the compound activates the pregnane- $\mathrm{X}$ receptor (PXR). It is recognized that induction of CYP2C enzymes can be important. For example, rifampicin is known to increase the clearance of S-warfarin (CYP2C9 substrate), a narrow therapeutic index drug (Bidstrup et al., 2004); however, challenges remain with generating reproducible in vitro CYP2C induction data, with a large enough induction signal across different lots of human donors, which can be used to assess the clinical risk of CYP2C induction. Thus, could we consider alternative approaches to assess the CYP2C induction risk? Also, the EMA guidelines on DDI (http:// www.ema.europa.eu/docs/en_GB/document_library/Scientific_guideline/2012/07/WC500129606.pdf) states that "strong inducers should be included as positive controls to verify functioning regulation pathways via PXR, constitutive androstane receptor (CAR), and the aryl hydrocarbon receptor (AhR)." CITCO, at concentrations $\leq 100 \mathrm{nM}$, is the positive control recommended by the EMA for CAR induction in in vitro experiments, in contrast to the FDA guidance, which recommends phenobarbital (PB) at a concentration between 500 and $1000 \mu \mathrm{M}$ as a positive control for induction of CYP2B6. Could either option be suitable to verify functioning CAR activity?

To address the aforementioned discussion points, the IWG approached IQ member companies as to which specific aspects of the recent DDI guidelines required further clarification and evaluation. The IWG then approached the EMA with questions developed from these responses requesting insights into the recommendations of the EMA and these questions were published online (http://www.ema.europa.eu/docs/ en_GB/document_library/Scientific_guideline/2009/09/WC500002963.pdf). As a follow-up, the IWG conducted an anonymous survey within IQ to gather information about current practices for the conduct of human hepatocyte induction studies and how companies interpret the derived data. Responses to the survey were received from 19 companies, which included 17 large companies ( $>10,000$ employees) and two mediumsized companies (1000-10,000 employees). Information gathered from the survey is presented in this article, together with data-driven recommendations on suggested changes to current regulatory guidance.
Given the complexity and detailed assessment necessary for the data interpretation and the time-course objectives, we plan to publish this work in follow-up articles.

\section{Materials and Methods}

The results presented in this article were obtained by conducting a survey of pharmaceutical companies that are members of the IQ Consortium. Survey questions were provided by members of the IWG (https://iqconsortium.org/ initiatives/working-groups/induction/). The questionnaires were formulated using Microsoft Excel (2010). Questions included single/multiple choice and openended or free text. The final survey was aimed at gathering information in five different areas: 1) evaluation of downregulation, 2) in vitro assessment of CYP2C induction, 3) use of CITCO as the positive control for CYP2B6 induction by CAR, 4) data interpretation (2-fold increase in mRNA as evidence of induction), and 5) duration of incubation of hepatocytes with test article. Data and information were collected for both nonproprietary and proprietary compounds. In some instances, certain questions had a small degree of overlapping information but were collated in the area that provided the best context for the question. Protocol questions focused on how studies were conducted by different organizations, which provided information on data variability across companies. In addition, induction data were collected for individual batches of hepatocytes such that variability across batches could also be assessed and to assess CYP2B6 induction by CITCO and phenobarbital. In these cases, all data were generated using standard internal company methods. Data were also collected to ascertain the manner in which in vitro hepatocyte induction data were interpreted by different companies. Given that establishing an in vitro to in vivo extrapolation (IVIVE) was critical, in addition to collecting in vitro data, clinical data were also collected and collated. Finally, the team also sought to understand the types of questions that were received from regulators related to induction. This part of the survey was conducted using an online questionnaire and survey software (SurveyMonkey; www.surveymonkey.com).

The survey was conducted anonymously via the IQ Secretariat and sent to representatives of IQ Consortium member companies. Each representative was responsible for providing responses that were reflective of the company as a whole since only one response was collected from each company. The IWG received the blinded responses from the IQ Secretariat and could not identify specific responses from specific companies. Survey limitations include the following: 1) the survey responses were blinded by the IQ Secretariat, which is a requirement for conducting surveys within the IQ consortium; therefore, it is not possible to follow up with respondents to clarify information or data entries, and so forth; 2) the survey was sent to the Drug Metabolism Leadership Group representative of each member company with the request to have an internal expert complete the survey with appropriate input from others to represent the company's perspective and not that of the individual reporter; it was not possible to ensure that this was conducted as requested; 3) IQ members may not have responded to all questions in the survey, and so, it is not possible to assess whether this introduced any bias in the survey responses; 4) the IQ Induction Working Group tried to provide clear questions; as with all blinded surveys, it is not possible to assess whether the respondent interpreted the question differently; 5) the survey was intended as a touch point to gain some insights into practices. The outcome of the survey is being used as one part of a strategy to develop a data-based response to specific aspects of regulatory DDI guidance. The survey responses are not considered a definitive index of induction practices within the pharmaceutical industry. The collection of responses occurred during the third quarter of 2015. Data analysis and graphs were generated using Microsoft Excel (2010, Microsoft Corporation, Renton, WA) or GraphPad Prism 6.0 (GraphPad Software, La Jolla, CA).

\section{Results}

Evaluation of Downregulation. Responses from the survey indicated that most companies use monolayer cultures (12 of 16 responses), a 96-well plate format (11 of 16 responses), and 48-hour exposure (12 of 16 responses) to test compounds (Fig. 1A). The survey confirmed that decreases in mRNA and/or enzyme activity mediated by NCEs are observed [downregulation and negative control survey; Part 2. Observations of downregulation (https://iqconsortium.org/initiatives/ 


\section{A Form at}

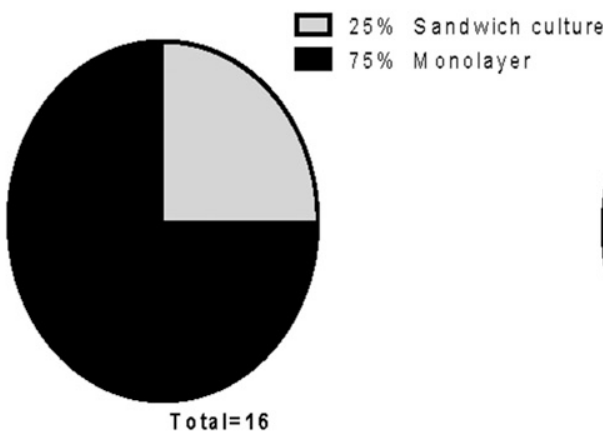

\# of wells

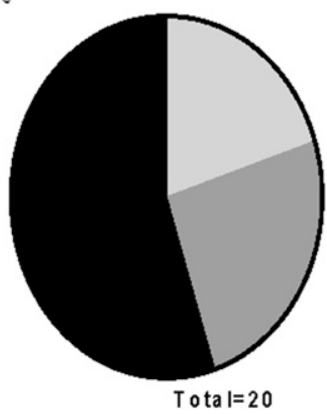

Time point (hour)

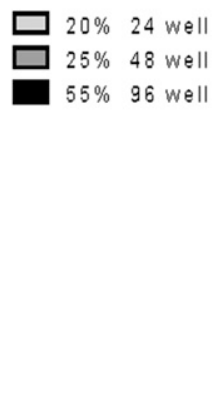

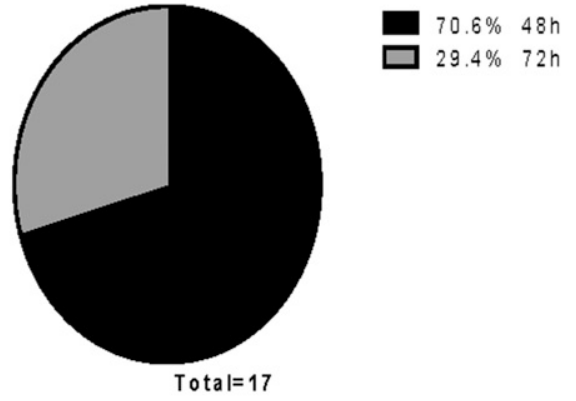

B Cytotoxicity Method Enzymes affected

C
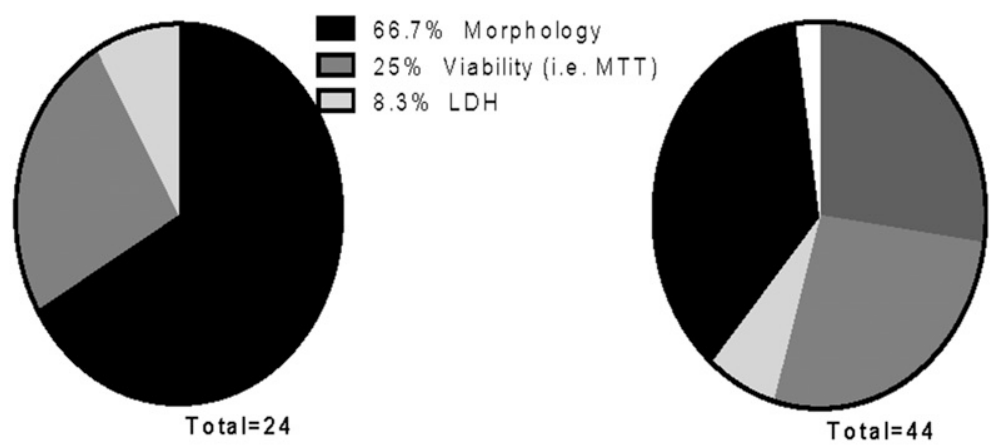

$27.3 \%$ CYP1A2

$27.3 \% \quad C Y P 2 B 6$

$6.8 \%$ CYP $2 C 8 / 9$

$36.4 \%$ CYP3A4

$2.3 \%$ UGT $1 A 1$

\section{Fold change mRNA Fold change activity}

$\%$ observation
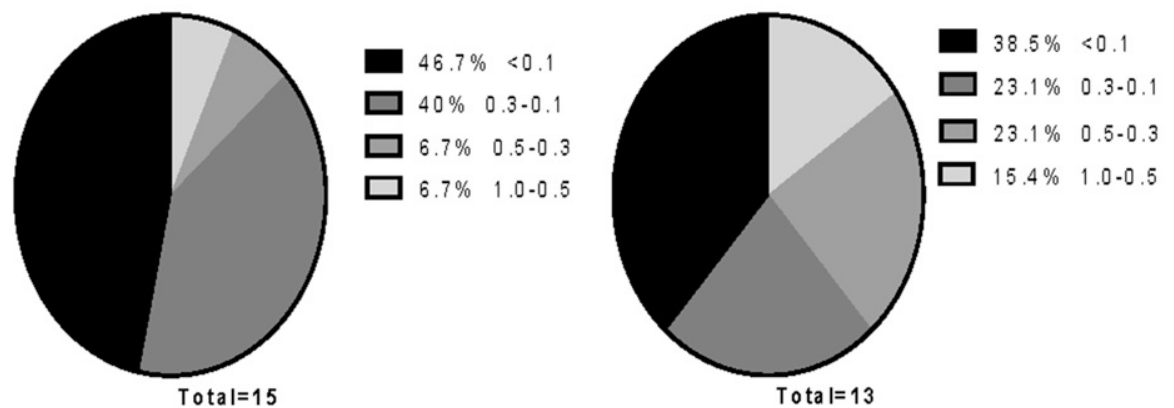

total induction studies

Fig. 1. Results from an IQ member survey focused on observations of in vitro downregulation or suppression. (A)Highlights the number of responses and the distribution for culture format, number of wells, and length of exposure to test compound. (B) Highlights the number of responses and the distribution for the type of cytotoxicity method run during the induction study and the enzymes where decreased levels were observed. (C) Highlights the number of responses and the distribution for the magnitudes of decreases observed for mRNA and enzyme activity levels, as well as the percentage of standard induction studies where observations of downregulation and suppression are made.

working-groups/induction/)]. Of the 17 respondents, 16 indicated that they have observed decreases in enzyme activity or mRNA levels during routine induction studies. In many cases, companies use multiple formats and cytotoxicity methods and have observed decreases in multiple enzymes so the total is not always equal to the number of respondents (17). In nearly half of all companies, $10 \%-20 \%$ of compounds screened for induction potential showed decreases in mRNA levels that were concentration-dependent, unrelated to cytotoxicity, and occurred across the enzymes evaluated (typically, CYP1A2, CYP2B6, and CYP3A4), whereas a few companies also evaluated other enzymes and noted commensurate decreases (CYP2C8, CYP2C9, and UGT1A1) (Fig. 1B). Thirteen companies observed decreases in mRNA $<0.3$-fold, of which seven companies showed changes $<0.1$ (Fig. 1C). In general, changes in mRNA levels appeared to be more sensitive than changes in enzyme activity. In most cases (7 of 11 responses), there was no clear correlation with structures, therapeutic area, or compound class when 
decreases in mRNA or activity were observed. Decreases in enzyme activity observed during routine in vitro induction studies can often be attributed to time-dependent inhibition (TDI) occurring over the incubation time course (Fahmi et al., 2010), as noted by seven companies in the survey. In addition, when decreases in mRNA or enzyme activity are observed only at higher concentrations of an NCE, cytotoxicity is often a plausible mechanism that should be evaluated; eight companies noted this as the mechanism. In cases where decreases in mRNA and/or enzyme activity are concentration-dependent and not related to TDI or cytotoxicity, mechanistic studies could potentially aid in identifying the cause(s). Mechanisms that have been shown to mediate downregulation of enzymes in vitro and/or in vivo could serve as a basis for designing follow-up studies (Dvorak et al., 2005; Healan-Greenberg et al., 2008; Lim et al., 2012; Lu et al., 2012).

Of the 17 responding companies, nine had no established cutoff criteria for downregulation, and the remaining companies used similar cutoff criteria, which included both $>50 \%$ decrease and concentration dependence. Only three companies performed follow-up mechanistic studies. Two of these studies involved a preclinical study in rats in which compound was administered and ex vivo mRNA levels and microsomal enzyme activity were measured. Because of variability in response, one study was deemed inconclusive. In the other study, downregulation of drug-metabolizing enzymes (DMEs) in rat hepatocytes had occurred at much higher concentrations of the NCE than was observed in human hepatocytes. In an ex vivo rat study, doses were selected that resulted in total systemic concentrations greater than the nominal in vitro incubation concentrations at which downregulation was observed. In the prepared extracts, from treated rat livers, no changes in microsomal enzyme activity or mRNA levels were observed. Hence, it was concluded that, in the rat, the in vitro downregulation did not translate to an in vivo effect. No companies currently use positive control compounds that have been shown to lead to downregulation of enzyme activity and mRNA in vitro. Indeed, the lack of small-molecule positive controls, where the underlying mechanism of downregulation is fully understood, significantly limits the ability to validate models for assessing downregulation. Overall, three companies chose to conduct a clinical interaction study based on the NCE-mediated downregulation observed in vitro. No companies showed clinical significance of these in vitro observations. Two of 16 companies gave examples of an attempt being made to relate the in vitro-derived parameters (fit similarly to induction data) to the expected clinical concentration. In one case, no clinical effect was anticipated, and only a moderate inhibition was anticipated in the other.

In addition to responding to the questionnaire, IQ member companies were asked to provide example questions received from regulators that were related to induction-based DDIs. Fourteen questions were submitted that were directly related to induction. Of these 14 questions, four were specifically targeted to gain a better understanding of NCEmediated decreases in mRNA levels and enzyme activities observed during in vitro induction studies with human hepatocytes. Regulators' questions probed for both mechanistic insights and extrapolation to other enzymes that potentially could be downregulated. Similar to TDI, downregulation could result in exposure increases in patients. One regulatory question related to a small molecule that demonstrated decreases in mRNA levels and enzyme activity during the in vitro induction study and also showed in vitro TDI of some of the same enzymes. In that study, time-dependent decreases in activity for many of the enzymes evaluated were observed in a cocktail clinical DDI study and the applicant was asked to discuss whether downregulation could be excluded as an additional mechanism and, if it could not, which other enzymes might be affected.

In Vitro Assessment of CYP2C Induction. Ten companies responded to questions related to CYP2C induction. Similar to data in the literature (Yajima et al., 2014), all companies reported variable CYP2C9 induction responses across different lots of hepatocytes, with induction values for $\mathrm{CYP} 2 \mathrm{C} 9$ that were $<4$-fold higher than vehicle control. Also, consistent with the literature, robust induction of CYP3A4 mRNA (12- to 47-fold) was observed in the same batches of hepatocytes (Fig. 2; Table 1 and 2) (Yajima et al., 2014). To negate the impact of protocol differences on the observed CYP2C mRNA inductive response between human hepatocyte donors, data were obtained from the same member company in 10 different batches of hepatocytes (Fig. 3). Again, whereas the CYP3A4 mRNA induction response to rifampicin was robust (8- to 80-fold), the extent of CYP2C8 and CYP2C9 mRNA induction ranged between 2- to 6-fold and 1.5- to 4-fold, respectively. Although the CYP2C8 and CYP2C9 mRNA induction responses were low, there was a good correlation with the observed functional changes in enzyme activity. The survey results demonstrate a low magnitude of induction of CYP2C8 and CYP2C9 mRNA.

In contrast, data from the survey showed that increases in CYP2C19 activities were highly variable and quite dramatic in some donors, up to 17-fold (Fig. 3). In addition to data obtained with rifampicin, the IWG compiled in vitro induction data for other compounds known to induce CYP2C isoforms (Supplementary Table 1). Given that the pathways involved in the regulation of CYP2C and CYP3A4 are similar, it was not surprising to see positive correlations for induction between CYP3A4 and CYP2C mRNA, with $r^{2}$ values ranging from 0.6 to 0.99 . Representative correlation plots for CYP2C and CYP3A4 enzymes, after induction by rifampicin, are shown in Fig. 4. This positive correlation can also be observed for bosentan, phenytoin, and carbamazepine, which cause varying extents of area under the curve (AUC) decline of CYP2C9 probe substrates and CYP3A4 probe substrates in the clinic (Table 3). Data in Table 3 summarize the percentage of

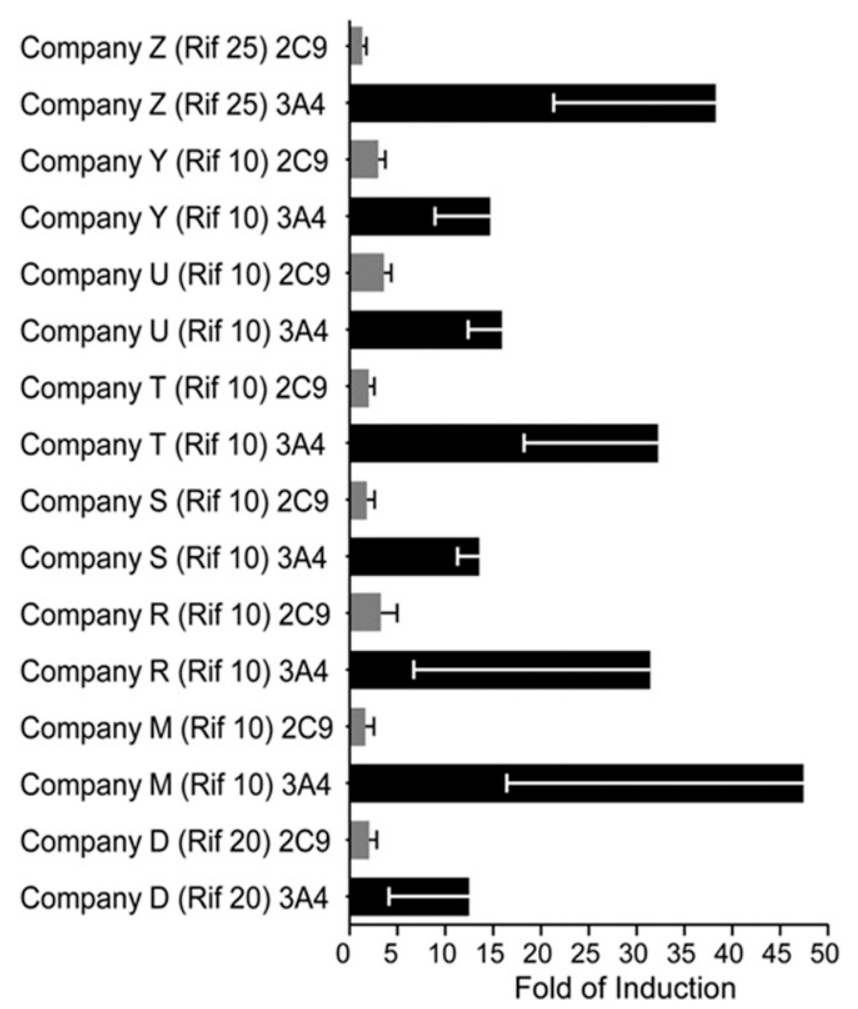

Fig. 2. CYP3A4 and CYP2C9 mRNA induction data obtained from the same donors after hepatocyte incubations with rifampicin. Data were obtained from eight respondents. 
TABLE 1

DDIs with perpetrator compounds that induce CYP2C

\begin{tabular}{|c|c|c|c|c|c|}
\hline Victim & Perpetrator & $\%$ Change AUC & Victim Dose (Oral) & Perpetrator Dose (Oral) & References \\
\hline Tolbutamide CYP2C9 in vivo probe & Aprepitant & -30.8 & $500 \mathrm{mg}$ & $125 / 80 \mathrm{mg}$ (3 days) & (Shadle et al., 2004) \\
\hline Tolbutamide CYP2C9 in vivo probe & Rifampicin & -62.5 & $500 \mathrm{mg}$ & $600 \mathrm{mg}$ (14 days) & (Adams et al., 2005) \\
\hline Tolbutamide CYP2C9 in vivo probe & Ritonavir & -50.5 & $500 \mathrm{mg}$ & $200-400 \mathrm{mg}$ (average of 14 days) & (Kirby et al., 2011) \\
\hline (S)-warfarin CYP2C9 in vivo probe & Bosentan & -29.3 & $26 \mathrm{mg}$ & $500 \mathrm{mg}$ (10 days) & (Weber et al., 1999) \\
\hline (S)-warfarin CYP2C9 in vivo probe & Dalcetrapib & -14 & $5 \mathrm{mg}$ of racemic warfarin & 900 mg (7 days) & (Derks et al., 2009) \\
\hline (S)-warfarin CYP2C9 in vivo probe & Rifampicin & -74.4 & $0.75 \mathrm{mg} / \mathrm{kg}$ & $300 \mathrm{mg}$ (14 days) & (Heimark et al., 1987) \\
\hline (S)-warfarin CYP2C9 in vivo probe & Ritonavir & -24.3 & $10 \mathrm{mg}$ & $100 \mathrm{mg}$ (14 days) & (Morcos et al., 2013) \\
\hline Repaglinide CYP2C8 in vivo probe & Rifampicin & -79.6 & $4 \mathrm{mg}$ & $600 \mathrm{mg}$ (7 days) & (Bidstrup et al., 2004) \\
\hline Repaglinide CYP2C8 in vivo probe & Flucloxacillin & -46.8 & $4 \mathrm{mg}$ & $500 \mathrm{mg}$ (7 days) & (Du et al., 2013) \\
\hline Omeprazole CYP2C19 in vivo probe & Arbamazepine & -39.7 & $20 \mathrm{mg}$ & $400-600 \mathrm{mg} /$ day (3 weeks) & (Bertilsson et al., 1997) \\
\hline Omeprazole CYP2C19 in vivo probe & Efavirenz & -46.4 & $20 \mathrm{mg}$ & $600 \mathrm{mg}$ (17 days) & (Michaud et al., 2012) \\
\hline Omeprazole CYP2C19 in vivo probe & Enzalutamide & -70.5 & $20 \mathrm{mg}$ & $160 \mathrm{mg}$ ( 85 days) & (Gibbons et al., 2015) \\
\hline Omeprazole CYP2C19 in vivo probe & Rifampicin & -93 & $10 \mathrm{mg}$ & $600 \mathrm{mg}$ (7 days) & (Derungs et al., 2016) \\
\hline
\end{tabular}

reduction of the AUC of an in vivo CYP2C9 probe, S-warfarin, in response to various xenobiotics and the in vitro induction of CYP2C and CYP3A evoked by the same compounds. Rifampicin caused the greatest decrease in the AUC of S-warfarin and also induced CYP3A4 more than the other compounds did.

Positive Control for CYP2B6 Induction by CAR. Data were provided by three member companies from 26 human hepatocyte donors showing CYP2B6 mRNA expression data after treatment with $100 \mathrm{nM}$ CITCO and with $\geq 750 \mu \mathrm{M}$ PB (Fig. 5). Both treatments demonstrated a $>2$-fold increase in CYP2B6 mRNA compared with vehicle control in all donors. The smallest increases observed in CYP2B6 mRNA with CITCO or PB treatment were 2.25-fold and 7.04-fold, respectively. In 23 of the 26 donors, the increase in CYP2B6 mRNA was greater after PB treatment compared with CITCO. The ratio of induction of CYP2B6 by PB compared with CITCO ranged from 0.87 to 4.08 .

\section{Discussion}

Transcriptional downregulation of $\mathrm{P} 450$ s by chemicals was identified as an area requiring further exploration more than 10 years ago (Riddick et al., 2004). Despite this finding, published observations of druginduced downregulation by small molecules in vitro are scarce (HealanGreenberg et al., 2008; Krausova et al., 2011; Yang et al., 2014; ZamekGliszczynski et al., 2014; Sager et al., 2017). Whereas potential mechanisms for downregulation have been identified (as detailed later herein), none has established a clinical effect for the major inducible enzymes (CYP1A2, CYP2B6, CYP2C, or CYP3A) from these in vitro observations. Indeed, when member companies were questioned as to whether the in vitro observations of downregulation led to clinical changes in specific probe substrates, no examples were provided. The EMA indicated that they had one example from a sponsor who reported that downregulation observed in human hepatocytes resulted in a clinical finding. Because of the confidentiality of the submissions, additional details on this compound are not available at this time. A recent publication concluded that the IVIVE for bupropion-mediated inhibition of CYP2D6 could be quantitatively predicted with the inclusion of downregulation (Sager et al., 2017); however, the mechanisms behind the CYP2D6 downregulation were not identified. Conflicting results are reported in the literature with respect to the inducibility of CYP2D6. Whereas CYP2D6 is generally thought not to be inducible (IngelmanSundberg, 2005; Teh and Bertilsson, 2012; Haertter, 2013), a recent publication shows that it can be induced in hepatocyte cultures in the absence of dexamethasone (Farooq et al., 2016). More work is needed to confirm the in vitro observations from these two studies and to explore the mechanisms for regulation of CYP2D6. No data on CYP2D6 induction or downregulation were collected from the IQ group members during this survey because evaluation of CYP2D6 induction was not conducted (http://www.ema.europa.eu/docs/en_GB/document_library/ Scientific_guideline/2012/07/WC500129606.pdf; http://www.fda.gov/ downloads/drugs/guidancecomplianceregulatoryinformation/guidances/ucm292362.pdf; MHLW, 2014).

In vitro induction studies are conducted using plated human hepatocytes either with (sandwich culture) or without matrix overlay (monolayer). Although hepatocytes are considered the gold standard for performing in vitro $\mathrm{P} 450$ induction studies, there are losses in enzyme activity for standard two-dimensional, monolayer) and sandwich

TABLE 2

Compounds reported to perpetrate CYP2C induction-based DDIs also perpetrate CYP3A4 induction-based DDIs

\begin{tabular}{|c|c|c|c|c|c|}
\hline Victim & Perpetrator (Oral) & $\%$ Change AUC & Victim Dose & Perpetrator Dose & References \\
\hline Simvastatin CYP3A in vivo probe & Bosentan & -34.4 & 40 mg (5.5 days) & $\begin{array}{r}125 \mathrm{mg} \\
(5.5 \text { days })\end{array}$ & (Dingemanse et al., 2003) \\
\hline Simvastatin CYP3A in vivo probe & Carbamazepine & -74.5 & $80 \mathrm{mg}$ & $\begin{array}{l}300 \mathrm{mg} \\
\text { (14 days) }\end{array}$ & (Ucar et al., 2004) \\
\hline Simvastatin CYP3A in vivo probe & Rifampicin & -91.0 & $40 \mathrm{mg}$ & $\begin{array}{l}600 \mathrm{mg} \\
(9 \text { days })\end{array}$ & (Chung et al., 2006) \\
\hline Simvastatin CYP3A in vivo probe & Rifampicin & -86.1 & $40 \mathrm{mg}$ & $\begin{array}{l}600 \mathrm{mg} \\
(5 \text { days })\end{array}$ & (Kyrklund et al., 2000) \\
\hline Simvastatin CYP3A in vivo probe & Troglitazone & -37.7 & $\begin{array}{r}40 \mathrm{mg} \\
(10 \text { days })\end{array}$ & $\begin{array}{c}400 \mathrm{mg} \\
\text { (24 days) }\end{array}$ & (Prueksaritanont et al., 2001) \\
\hline Sildenafil CYP3A in vivo Probe & Bosentan & -69.0 & $100 \mathrm{mg}$ & $\begin{array}{l}62-125 \mathrm{mg} \\
(8 \mathrm{wk})\end{array}$ & (Paul et al., 2005) \\
\hline Midazolam CYP3A in vivo probe & Rifampicin & -98.4 & $7.5 \mathrm{mg}$ & 600 mg (6 days) & (Link et al., 2008) \\
\hline
\end{tabular}



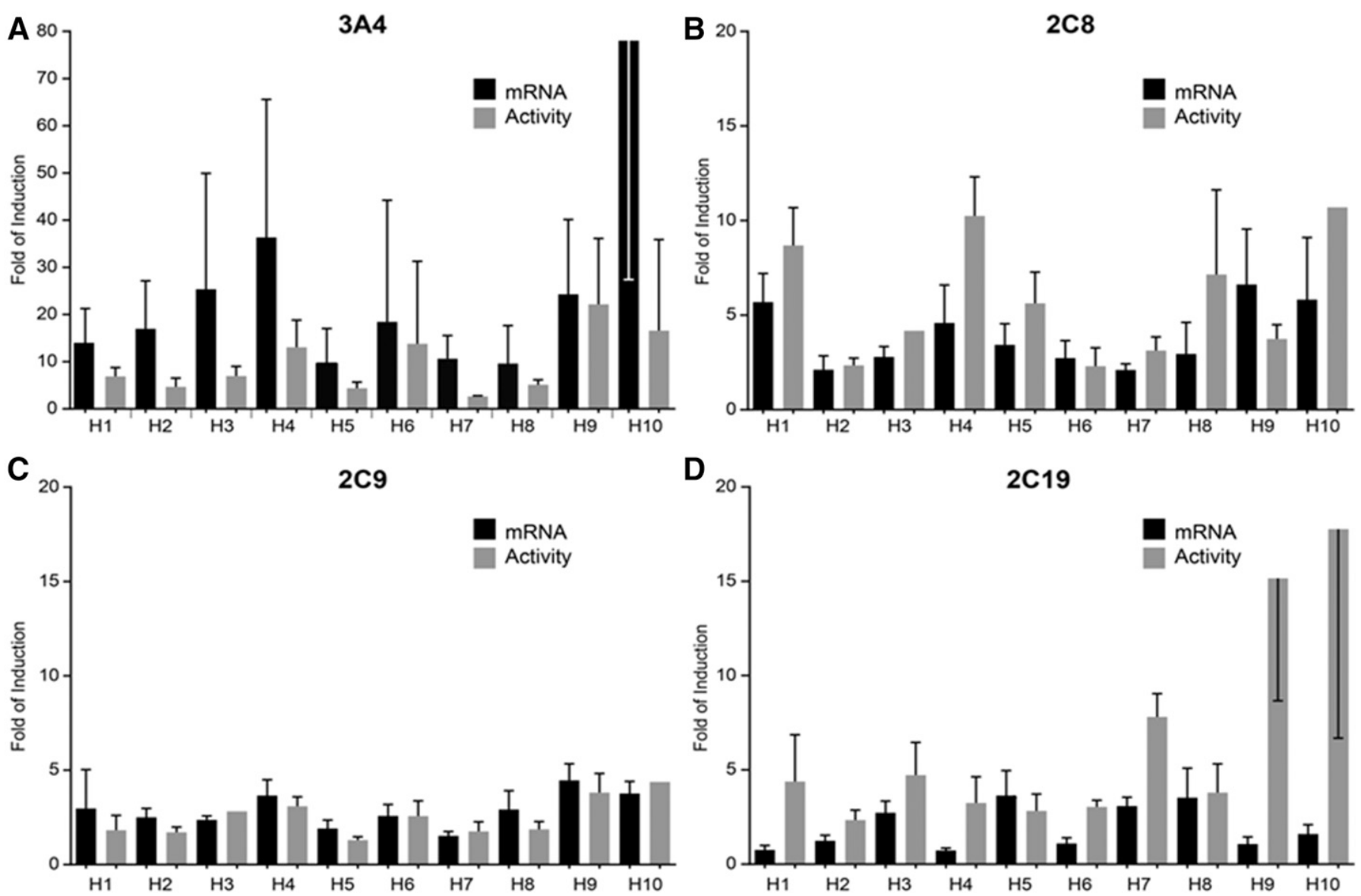

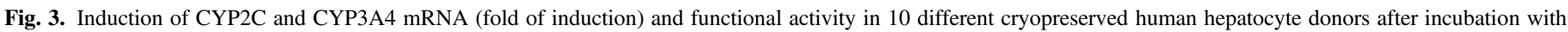
rifampicin at $10 \mu \mathrm{M}$. Data obtained from one respondent.

cultured primary human hepatocytes over culture time resulting in a lower basal P450 activity compared with freshly isolated suspension hepatocytes (LeCluyse et al., 2000; Hamilton et al., 2001; PichardGarcia et al., 2002; Rodriguez-Antona et al., 2002; Aitken et al., 2006; Hewitt et al., 2007b; Fardel and Le Vee, 2009; Huang et al., 2010; Lee et al., 2010). The exact mechanisms for the enzyme loss are not clear, but recent articles highlight an important role of micro-RNAs (miRNAs) as drivers of hepatic dedifferentiation and demonstrate a complete change in the proteome of standard two-dimensional cultures (Bell et al., 2016; Lauschke et al., 2016). Would long-term hepatocyte models offer advantages to evaluate downregulation? Models have been developed that aim to improve the longevity and maintenance of activity of DMEs and include coculture models (Khetani and Bhatia, 2008; Krause et al., 2009), organotypic models (LeCluyse et al., 2012), three-dimensional spheroid (Bell et al., 2016), and flow systems (Soldatow et al., 2013); however, these models have not been as rigorously tested for induction as standard cultured hepatocyte models have been. Therefore, routine induction studies that satisfy current regulatory requirements are performed using sandwich cultured or monolayer hepatocytes. Although reduced enzyme expression levels and activity offer a robust response window for induction, adequate basal levels are needed to characterize metabolism with and without downregulation (Evers et al., 2013). Differences in culture conditions can also impact the basal levels of DMEs and the ability of the culture to respond to cytotoxicity. An example was provided whereby the same unidentified company, using different culturing conditions at different sites, could not reproduce observed in vitro downregulation. The exact reason for this difference was not determined, but differences between sites in media formulations, plating format, donor used, and culturing techniques may have contributed. Additionally, the half-life of the endpoint being measured [mRNA or protein (enzyme activity)] compared with the incubation time course needs to be considered when interpreting in vitro data. Whereas the half-life for mRNA of a given enzyme is shorter than the half-life for enzyme (Ramsden et al., 2015; Dixit et al., 2016), there can be differential turnover observed between enzymes. As an example, differences in potency assessments for interleukin-6-mediated downregulation of CYP3A4 mRNA have been observed at between 48- and 72-hour incubation times (Evers et al., 2013).

There is also a potential for cytotoxicity to occur, especially with the high in vitro concentrations used during an induction study. High compound test concentrations aim to cover potential gut concentrations and achieve levels sufficient to describe $E_{\max }$ when induction is observed. Whereas cytotoxicity is typically assessed during induction studies, most researchers use morphologic assessment and endpoint assays, such as ATP, lactate dehydrogenase, MTT [(3-(4,5-dimethylthiazol-2-yl)-2,5-diphenyltetrazolium bromide)], Presto Blue (ThermoFisher Scientific, Waltham, MA), WST-1 (Clontech Laboratories, Inc., Mountain View, CA), or monitoring of a housekeeping gene by TaqMan (ThermoFisher Scientific) (Fig. 1B). These assays are capable of detecting overt cytotoxicity. In many cases, more sensitive assays would be required to rule out a link between early cytotoxic events and downregulation of enzymes. Setting stringent criteria for assessment of cytotoxicity (e.g., 20\%-25\% cutoff compared with control) could help to avoid assigning significance to downregulation that is the result of cytotoxicity. Depending on the mode of hepatocyte toxicity, other assays may be more or less sensitive, and this toxicity could also be 
A Company M: RIF Correlation

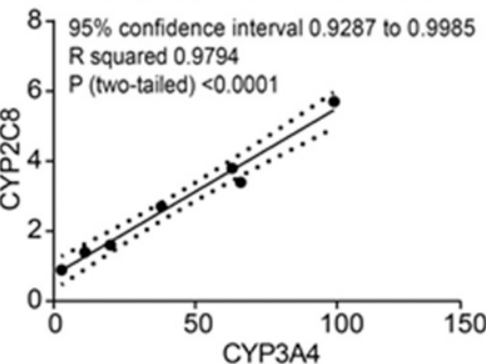

D Company M: RIF Correlation

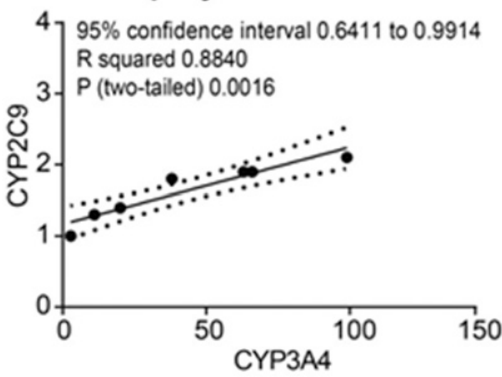

G Company M: RIF Correlation

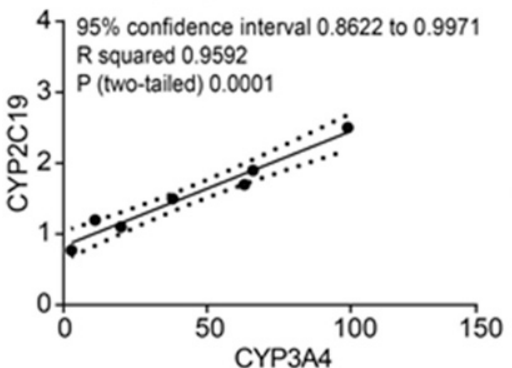

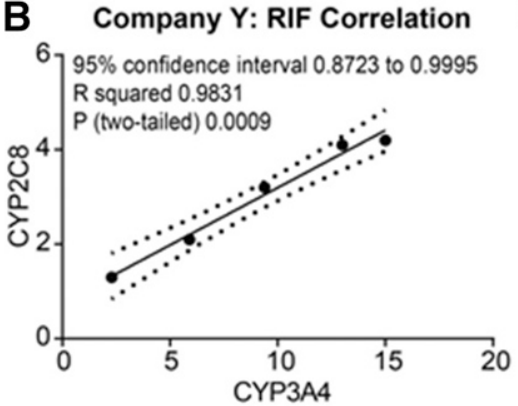

E Company Y: RIF Correlation

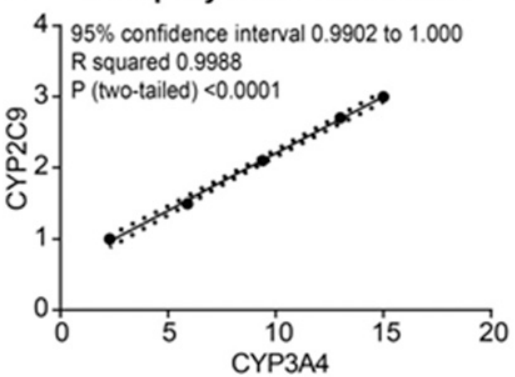

H Company Y: RIF Correlation

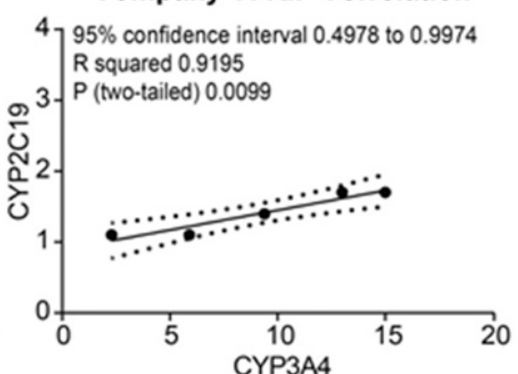

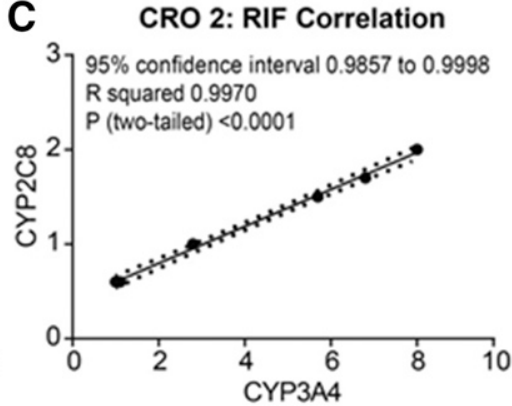

F CRO 2: RIF Correlation

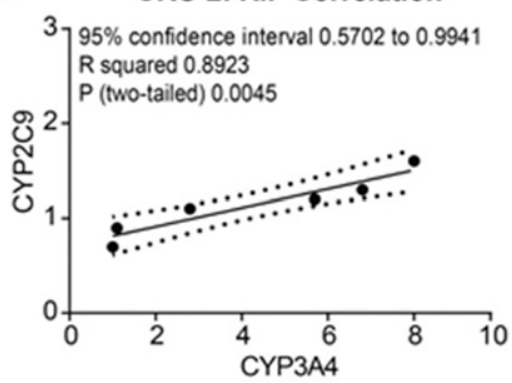

CRO 2: RIF Correlation

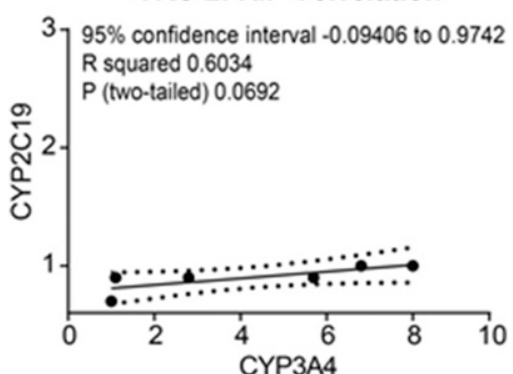

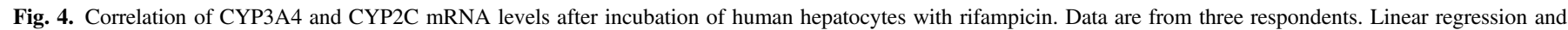
correlation analysis described in the plot were performed using Graph Pad Prism (version 6.04).

compound-dependent. There are potentially more sensitive approaches available to assess cytotoxicity, such as high-content imaging or systems such as xCelligence (ACEA Biosciences, San Diego, CA) (Gerets et al., 2012; Grimm et al., 2015; Joshi and Lee, 2015; Li et al., 2015). Overall, the potential for cytotoxicity to contribute to downregulation should be considered as part of the complete picture toward developing an understanding of mechanisms behind these observations.

Alterations of the levels of P450 isoforms can occur through modulation of steroid receptors, such as PXR, CAR, and AhR, with

TABLE 3

Comparison of mean $(n=3)$ fold of induction of CYP2C9 and CYP3A4 mRNA in vitro in human hepatocytes with reduction in S-warfarin or phenytoin AUC in vivo

\begin{tabular}{lrcc}
\hline Compound $(10 \mu \mathrm{M})$ & \multicolumn{1}{c}{ 2C 9} & 3A4 & 2C9\% AUC $\downarrow$ \\
\hline Rifampicin & $3(0.7)$ & $15(6)$ & $74.4^{a}$ \\
Bosentan & $3(0.5)$ & $13(3)$ & $29.3^{a}$ \\
Ritonavir & $2.6(0.2)$ & $10(3)$ & $24.3^{a}$ \\
Dalcetrapib $^{b}$ & $2.4(0.3)$ & $7.4(2.5)$ & $14^{a}$ \\
Vigabitran & $1.3(0.2)$ & $1.4(0.1)$ & $3.7^{c}$ \\
\hline
\end{tabular}

${ }^{a}$ Decrease in S-warfarin AUC.

${ }^{b} 100 \mu \mathrm{M}$.

${ }^{c}$ Phenytoin AUC.

Change in AUC data obtained from the University of Washington Drug-Drug Interaction Database (https://www.druginteractioninfo.org/).
PXR and CAR partly regulated by the glucocorticoid receptor (GR) (Honkakoski and Negishi, 2000). These signal transduction pathways can be affected at any step of the cascade, leading to P450 downregulation (e.g., interference with binding of nuclear receptor retinoid-X receptor with PXR) and disturbances with the cytoskeletal structure in the cell. A well known example of small-molecule-mediated downregulation in which these two mechanisms could be operative is that of colchicine, which has been shown to broadly reduce expression of $\mathrm{P} 450 \mathrm{~s}$, both in the basal state as well as in the induced state (Dvorak et al., 2003, 2005). Colchicine is an anti-tubulin agent that inhibits the polymerization of microtubulin and thus disrupts the dynamics of the microtubulin cellular skeletal structure, the structure that is considered necessary for the proper functioning of nuclear receptor signaling cascades ( $\mathrm{Lu}$ et al., 2012). A mechanistic study was conducted to understand the potential causes of the broad reduction of P450s and led to the hypothesis that GR is more readily affected by cytoskeletal disruption (Dvorak et al., 2005). Mechanistic explorations, in parallel with P450 modulation, could involve assessments of P-glycoprotein, multidrug resistance proteins (MRPs), uridine 5'-diphosphoglucuronosyltransferases, glutathione S-transferases, sulfotransferases, organic anion-transporting polypeptides, carboxyl esterases, and so forth, which are coregulated by these nuclear receptors (Urquhart et al., 2007; Chen et al., 2012). Specific knowledge gaps in this area include 1) the differential downregulation in the liver and gut;2) combined 


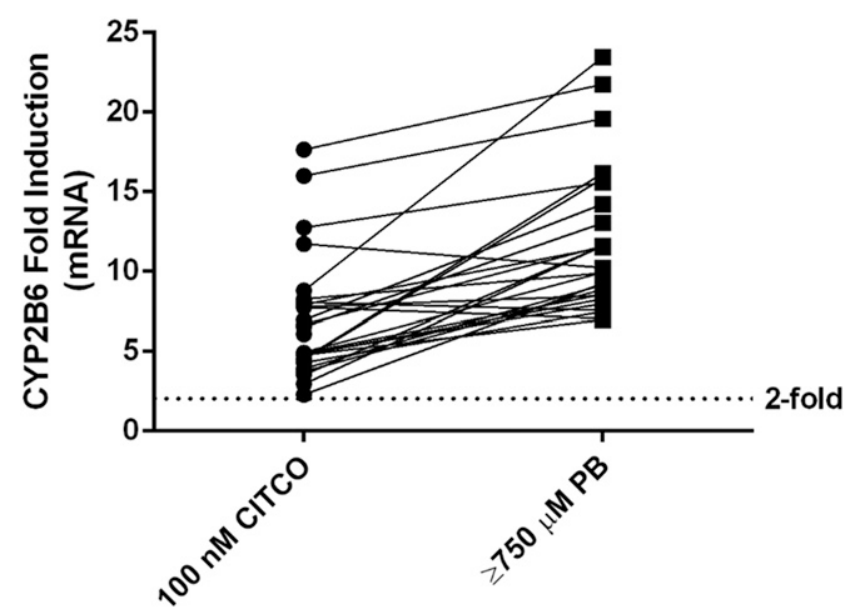

Fig. 5. Comparison of CYP2B6 induction between CITCO and phenobarbital in cultured human hepatocytes from 26 different donors.

downregulation of closely related enzymes, such as CYP3A5 along with CYP3A4; and 3) species differences in P450 downregulation. GR and hepatocyte nuclear factor- $\alpha$ are important for basal expression of multiple $\mathrm{P} 450 \mathrm{~s}$ and play a supportive role in classic induction (Pascussi et al., 2001). Their role in combined downregulation needs to be further explored. It can become even more challenging when mixed mechanisms of DDI are occurring. For instance, as highlighted by one of the regulatory questions, it would be quite difficult to differentiate downregulation of mRNA observed in vitro from TDI or to identify which mechanism or combination of mechanisms and their relative contributions led to the observed clinical changes. As highlighted already, more research in the area of downregulation is needed to evaluate whether mechanisms of downregulation can affect multiple enzymes analogously to coordinate induction of multiple enzymes (e.g., through PXR). This issue could be relevant since TDI may be isoformspecific, whereas downregulation could potentially affect multiple coregulated enzymes. In this case, when the mechanism of in vitro downregulation occurs at the nuclear receptor, consideration of coregulated enzymes, not affected by TDI, or modeling of effects based on clinical concentrations and in vitro parameters, $E C_{50}$ and $E_{\min }$, for the downregulation or $K_{\mathrm{I}}$ and $k_{\text {inact }}$ for TDI, might offer some insights.

Examples of small molecules that disrupt the interactions between nuclear receptors and coactivators involve sesamin in sesame oil (Lim et al., 2012), camptothecin (Chen et al., 2010), ketoconazole (Takeshita et al., 2002), and ET743 (Synold et al., 2001). Small molecules can serve as direct antagonists, inhibitors, or repressors of nuclear receptors. The PXR antagonist, A-792611 (Healan-Greenberg et al., 2008), causes P450 downregulation. Other examples of molecules that downregulate in vitro are LY2090314, sulforaphane, fluoxetine, norepinephrine, epinephrine, and riluzole (Zhou et al., 2007; Zamek-Gliszczynski et al., 2014; Badolo et al., 2015; Shang et al., 2016). Metformin has been shown to specifically enhance the phosphorylation of CAR, thus blocking nuclear translocation and activation (Yang et al., 2014). None of these example drugs resulted in clinical effects, either because downregulation did not manifest with a change in the exposure of clinical substrates or comedications or, like colchicine, because the clinical concentration was much lower than the concentrations where downregulation was observed in vitro.

Certainly, a key challenge for in vitro observations of decreases in mRNA or enzyme activity (not owing to inhibition) remains the translation of the in vitro findings to the clinic. Multiple rising-dose studies in healthy volunteers are often the first opportunity to evaluate downregulation clinically, but only if the pathway that is downregulated represents a major route of clearance. With the small number of individuals and the large variability that can occur with inducible human $\mathrm{P} 450 \mathrm{~s}$, these studies are typically not powered to provide definitive outcomes; however, it still may be possible to leverage this information as a means of developing an understanding of the predictability of such downregulation. Clinical plasma concentrations could provide a basis for identifying possible P450 downregulation if the P450 affected is a major clearance pathway for the compound itself and where these changes can be related to concentration dependence in the hepatocyte studies. As noted already herein, this was the case with colchicine, where no DDIs were observed with relevant drugs, probably owing to low systemic concentrations in humans (Colcrys, Package Insert, Takeda Pharmaceuticals, Cambridge, MA).

The challenges of describing downregulation in cultured hepatocytes are also reflected in the typically small signal for induction of CYP2C isoforms. A limited number of publications describe the induction of human CYP2C8, CYP2C9, and CYP2C19 using either fresh or cryopreserved hepatocytes (Gerbal-Chaloin et al., 2001; Raucy et al., 2002; Fahmi et al., 2010). Moreover, the reports on induction of CYP2C isoforms are contradictory. For example, induction of CYP2C9 and CYP2C19 by rifampicin in human hepatocytes has been documented (Zilly et al., 1975; Gerbal-Chaloin et al., 2001), but others have shown no induction (Li et al., 1997; Runge et al., 2000; Dixit et al., 2016). Recently, Yajima et al. (2014) evaluated the induction of human CYP2C8, CYP2C9, and CYP2C19 mRNA using eight lots of cryopreserved human hepatocytes. After 72-hour incubation with rifampicin, induction of CYP2C8 and CYP2C9 mRNA was variable, whereas induction of CYP2C19 mRNA was not observed in any of the eight hepatocyte lots tested. Our results are consistent with the observation by Yajima et al. (2014). Additionally, recent evidence suggests that miRNA may impact the basal expression of CYP2C8 and CYP2C19 in human hepatocytes (Yu et al., 2015; Makia and Goldstein, 2016). In vitro studies have also demonstrated that protein-protein interactions occur between CYP2C9 and CYP3A4, which result in lower CYP2C9 activity with increasing levels of CYP3A4 (Subramanian et al., 2010; Ramsden et al., 2014). In the human HepatoPac (Ascendance Biotechnology, Medford, MA) model, induction of CYP2C9 activity by rifampicin was greater when CYP3A4 levels were decreased by siRNA knockdown. Thus, the apparent induction of CYP2C9 was dependent on the ratio of CYP2C9:CYP3A4 protein expression levels (Ramsden et al., 2014). These factors may be responsible for the low magnitude and variable induction observed in our survey between the various CYP2C isoform mRNA induction responses. Additional mechanistic studies are needed to further understand the lack of robust induction and the variable response of CYP2C isoforms as determined by mRNA.

IVIVE approaches have been developed for the induction of CYP3A to predict the potential of a compound to cause a clinically relevant DDI if coadministered with a compound that is primarily metabolized by CYP3A4 (Einolf et al., 2014). Given that CYP3A4 shares transcriptional regulation factors with $\mathrm{CYP} 2 \mathrm{C}$, it may be possible to ascertain the risk of CYP2C induction based on the risk assessment for CYP3A4 induction using static and dynamic models (Einolf et al., 2014).

Both PB and CITCO are known CAR activators that have been shown to work through different mechanisms. Kawamoto et al. demonstrated that PB induced CYP2B genes by causing CAR to translocate from the cytoplasm to the nucleus, where it binds to the phenobarbital-responsive enhancer module and increases transcription of downstream genes (Kawamoto et al., 1999). Activation of CAR does not require direct binding of PB (Yang et al., 2014). This is in contrast to CITCO, which causes nuclear translocation by directly binding to the receptor (Xu et al., 2004). These observations have led to two proposed mechanisms of 
CAR activation: direct activation, which requires ligand binding, and indirect activation, which does not.

CYP2B6 induction can occur through activation of either CAR or PXR (Wang and Negishi, 2003). The ligand binding profile of PXR is known to include a diverse array of drug-like molecules, but the number of chemicals that activate CAR appears to be much less structurally diverse and shows considerable overlap with PXR activators (Mackowiak and Wang, 2016). To date, CITCO is the only chemical that has been shown to be highly selective for CAR over PXR. In transient transfection assays, CITCO displayed a $>100$-fold selectivity for CAR over PXR, with $\mathrm{EC}_{50}$ values of $25 \mathrm{nM}$ for $\mathrm{CAR}$ and $\sim 3 \mu \mathrm{M}$ for PXR (Maglich et al., 2003). In contrast, PB has been shown to activate both CAR and PXR (Kawamoto et al., 1999; Sinz et al., 2006), although the degree of receptor selectivity has not been quantified.

In primary human hepatocytes, it has been consistently shown that $100 \mathrm{nM}$ CITCO induces CYP2B6, a concentration that is unlikely to activate PXR due to the selectivity described above. Increases in CYP2B6 mRNA, after treatment with $100 \mathrm{nM}$ CITCO, were shown in 13 separate hepatocyte preparations (Maglich et al., 2003; DeKeyser et al., 2009; Sahi et al., 2009; Yang et al., 2010; Koh et al., 2012). Eleven of the 13 donors showed a $>2$-fold increase in mRNA. Based on the data provided, it could not be determined whether the remaining two donors met this threshold. Additional data collected for this survey add another 26 donors demonstrating a $>2$-fold increase in CYP2B6 mRNA by $100 \mathrm{nM}$ CITCO. Thus, of the 39 total donors evaluated, 37 showed a response to $100 \mathrm{nM}$ CITCO, defined as an increase in CYP2B6 mRNA $>2$-fold above vehicle control, a failure rate of approximately $5 \%$. These data strongly support that CAR remains functional in primary hepatocytes as used in typical induction experiments and that hepatocytes are an adequate in vitro model for the assessment of CYP2B6 induction through CAR. In contrast, immortalized hepatocyte cell lines, such as HepG2 and Fa2N4, lack CAR functionality (Kawamoto et al., 1999; Hariparsad et al., 2008). The data collected for this survey also demonstrated approximately equal or greater CYP2B6 induction by PB compared with CITCO across 26 donors. This additional increase in CYP2B6 may represent the contribution of PXR in addition to the CAR component. If so, PB should better represent the in vitro response of mixed activators of CAR and PXR.

The utility of these hepatocyte models increases greatly if IVIVE can be established, allowing for prediction of a clinical response from the in vitro data. In order for an in vitro model to be informative of an in vivo effect, it is necessary for the model to maintain the functional mechanisms through which that effect is manifested. Based on data presented here, it appears that primary human hepatocytes are adequate in this regard. Challenges have been noted in developing IVIVE for CYP2B6 induction (Fahmi et al., 2016), and it is currently unknown what effect, if any, the different mechanisms of CAR activation have on clinical outcome. As such, it is the opinion of the IWG that both CITCO and PB are viable positive controls for in vitro studies of CYP2B6 by CAR.

\section{Summary and Recommendations}

- When a decrease in mRNA or activity is observed in vitro, there should be careful consideration of whether the decrease is concentration-dependent and whether the compound is an inhibitor or an inactivator of the enzyme. Consideration should also be given to whether the decrease in mRNA or activity is linked to cytotoxicity or the mechanism of action.

- Correspondence with the EMA indicated that this agency does have experience with downregulation observed in human hepatocytes, which was confirmed in vivo for one compound from a sponsor.
- Establishing an IVIVE in the absence of compounds that cause clinically relevant decreases in enzyme activity as a result of down regulation of enzymes is currently not possible. As such, in vitro observations of downregulation have to be considered with caution.

- Given the variable and low dynamic range of response in human hepatocytes, accurately predicting the potential for DDIs owing to induction of CYP2C isoforms is challenging.

- Improved in vitro models with better dynamic range and less variability for the assessment of CYP2C induction are needed. Based on coregulatory pathways and positive correlation analyses, induction of CYP3A4 can be used as a sensitive marker of the potential for induction of CYP2C isoforms. Thus, a compound determined to have low risk to cause a CYP3A4-induction based DDI will have a very low risk of causing a CYP2C inductionbased DDI.

- Data from the literature, and new data provided in this survey, demonstrate that primary human hepatocytes largely maintain a functional CAR regulatory pathway and are a reliable tool for assessing CYP2B6 induction by CAR. The risk of missing a CAR activator, potentially as a result of decreased CAR functionality, is further mitigated by the use of three individual human donors for in vitro P450 induction studies as recommended by regulatory agencies. As such, the potential to have a false negative for CAR induction in a human hepatocyte study is very small.

- Both CITCO and PB are activators of CAR but work through different mechanisms, direct or indirect activation, respectively. It is currently unknown what clinical differences may be attributable to the different modes of action.

- The IWG recommends the use of either $100 \mathrm{nM}$ CITCO or $\geq 750$ $\mu \mathrm{M}$ PB as the positive control for CYP2B6 induction in human hepatocytes.

\section{Concluding Remarks}

P450 induction has gained wide acceptance as an important factor for consideration in drug development, particularly as it relates to DDI (Hewitt et al., 2007a; Chu et al., 2009). A number of factors have facilitated the emergence of human hepatocytes as the gold standard for the evaluation of P450 induction (Chu et al., 2009), including improvements in the cryopreservation of hepatocytes (Saliem et al., 2012) and the consequent availability of large batches of human hepatocytes that can be characterized before routine use. The availability of cryopreserved human hepatocytes, from the same donor, in sufficient abundance, has also enabled the development of calibration models (Fahmi et al., 2008), which provides greater confidence to regulators for risk-based decision making. The continued progress in the understanding of induction requires collaboration between regulatory agencies and pharmaceutical companies with the overall goal of designing and conducting the most appropriate, necessary, and insightful clinical induction studies. It needs to be ensured that the design of preclinical studies is optimal. This survey of IQ member companies on current practices is intended as a step toward this goal, which, together with recommendations, specifically as they relate to key questions such as downregulation, the in vitro assessment of CYP2C induction, as well as the use of CITCO as the in vitro CYP2B6 positive control will hopefully lead to optimized studies.

The IWG intends to publish our survey results and recommendations related to the data interpretation and the time-course objectives in follow-up articles. Our focus thus far has been to conduct an expanded analysis of clear positive and negative thresholds for in vitro induction. To this end, we set out to gather hepatocyte induction and clinical DDI 
data for both prototypical inducers and proprietary compounds. In addition, the IWG is also in the process of collating and generating primary hepatocyte $\mathrm{P} 450 \mathrm{mRNA}$ and activity time-course data to gather more information regarding the magnitude of induction response over time and to determine the robustness of the assay at shorter time points in comparison with the 72-hour incubation time recommended by the EMA.

\section{Authorship Contributions}

Participated in research design: Hariparsad, Ramsden, Palamanda, Dekeyser, Fahmi, Kenny, Einolf, Mohutsky, Pardon, Siu, Chen, Sinz, Jones, Walsky, Dallas, Balani, Zhang, Buckley, Tweedie.

Performed data analysis: Hariparsad, Ramsden, Palamanda, Dekeyser, Fahmi.

Wrote or contributed to the writing of the manuscript: Hariparsad, Ramsden, Palamanda, Dekeyser, Fahmi, Kenny, Einolf, Mohutsky, Pardon, Siu, Chen, Sinz, Jones, Walsky, Dallas, Balani, Zhang, Buckley, Tweedie.

\section{References}

Adams M, Pieniaszek, Jr HJ, Gammaitoni AR, and Ahdieh H (2005) Oxymorphone extended release does not affect CYP2C9 or CYP3A4 metabolic pathways. J Clin Pharmacol 45:337-345. Aitken AE, Richardson TA, and Morgan ET (2006) Regulation of drug-metabolizing enzymes and transporters in inflammation. Аnпи Rev Pharmacol Toxicol 46:123-149.

Badolo L, Jensen B, Säll C, Norinder U, Kallunki P, and Montanari D (2015) Evaluation of 309 molecules as inducers of CYP3A4, CYP2B6, CYP1A2, OATP1B1, OCT1, MDR1, MRP2, MRP3 and BCRP in cryopreserved human hepatocytes in sandwich culture. Xenobiotica 45 177-187.

Bell CC, Hendriks DF, Moro SM, Ellis E, Walsh J, Renblom A, Fredriksson Puigvert L, Dankers AC, Jacobs F, Snoeys J, et al. (2016) Characterization of primary human hepatocyte spheroids as a model system for drug-induced liver injury, liver function and disease. Sci Rep 6:25187-25200.

Bertilsson L, Tybring G, Widén J, Chang M, and Tomson T (1997) Carbamazepine treatment induces the CYP3A4 catalysed sulphoxidation of omeprazole, but has no or less effect on hydroxylation via CYP2C19. Br J Clin Pharmacol 44:186-189.

Bidstrup TB, Stilling N, Damkier P, Scharling B, Thomsen MS, and Brøsen K (2004) Rifampicin seems to act as both an inducer and an inhibitor of the metabolism of repaglinide. Eur J Clin Pharmacol 60:109-114

Bjornsson TD, Callaghan JT, Einolf HJ, Fischer V, Gan L, Grimm S, Kao J, King SP, Miwa G, Ni L, et al.; Pharmaceutical Research and Manufacturers of America Drug Metabolism/Clinical Pharmacology Technical Working Groups (2003) The conduct of in vitro and in vivo drug-drug interaction studies: a PhRMA perspective. J Clin Pharmacol 43:443-469.

Chen Y, Tang Y, Guo C, Wang J, Boral D, and Nie D (2012) Nuclear receptors in the multidrug resistance through the regulation of drug-metabolizing enzymes and drug transporters. Biochem Pharmacol 83:1112-1126.

Chen Y, Tang Y, Robbins GT, and Nie D (2010) Camptothecin attenuates cytochrome P450 3A4 induction by blocking the activation of human pregnane $\mathrm{X}$ receptor. J Pharmacol Exp Ther 334 999-1008

Chu V, Einolf HJ, Evers R, Kumar G, Moore D, Ripp S, Silva J, Sinha V, Sinz M, and Skerjanec A (2009) In vitro and in vivo induction of cytochrome p450: a survey of the current practices and recommendations: a pharmaceutical research and manufacturers of america perspective. Drug Metab Dispos 37:1339-1354.

Chung E, Nafziger AN, Kazierad DJ, and Bertino, Jr JS (2006) Comparison of midazolam and simvastatin as cytochrome P450 3A probes. Clin Pharmacol Ther 79:350-361.

DeKeyser JG, Stagliano MC, Auerbach SS, Prabhu KS, Jones AD, and Omiecinski CJ (2009) Di(2ethylhexyl) phthalate is a highly potent agonist for the human constitutive androstane receptor splice variant CAR2. Mol Pharmacol 75:1005-1013

Derks M, Fowler S, and Kuhlmann O (2009) In vitro and in vivo assessment of the effect of dalcetrapib on a panel of CYP substrates. Curr Med Res Opin 25:891-902.

Derungs A, Donzelli M, Berger B, Noppen C, Krähenbühl S, and Haschke M (2016) Effects of cytochrome P450 inhibition and induction on the phenotyping metrics of the Basel cocktail: a Randomized crossover study. Clin Pharmacokinet 55:79-91.

Dingemanse J, Schaarschmidt D, and van Giersbergen PL (2003) Investigation of the mutual pharmacokinetic interactions between bosentan, a dual endothelin receptor antagonist, and simvastatin. Clin Pharmacokinet 42:293-301.

Dixit V, Moore A, Tsao H, and Hariparsad N (2016) Application of micropatterned cocultured hepatocytes to evaluate the inductive potential and degradation rate of major xenobiotic metabolizing enzymes. Drug Metab Dispos 44:250-261.

Du QQ, Wang ZJ, He L, Jiang XH, and Wang L (2013) PXR polymorphisms and their impact on pharmacokinetics/pharmacodynamics of repaglinide in healthy Chinese volunteers. Eur J Clin Pharmacol 69:1917-1925.

Dvorak Z, Modriansky M, Pichard-Garcia L, Balaguer P, Vilarem MJ, Ulrichová J, Maurel P, and Pascussi JM (2003) Colchicine down-regulates cytochrome P450 2B6, 2C8, 2C9, and 3A4 in human hepatocytes by affecting their glucocorticoid receptor-mediated regulation. $\mathrm{Mol}$ Pharmacol 64:160-169.

Dvorák Z, Ulrichova J, and Modriansky M (2005) Role of microtubules network in CYP genes expression. Curr Drug Metab 6:545-552.

Einolf HJ, Chen L, Fahmi OA, Gibson CR, Obach RS, Shebley M, Silva J, Sinz MW, Unadkat JD, Zhang L, et al. (2014) Evaluation of various static and dynamic modeling methods to predict clinical CYP3A induction using in vitro CYP3A4 mRNA induction data. Clin Pharmacol Ther 95:179-188.

Evers R, Dallas S, Dickmann LJ, Fahmi OA, Kenny JR, Kraynov E, Nguyen T, Patel AH, Slatter JG, and Zhang L (2013) Critical review of preclinical approaches to investigate cytochrome p450-mediated therapeutic protein drug-drug interactions and recommendations for best practices: a white paper. Drug Metab Dispos 41:1598-1609.

Fahmi OA, Boldt S, Kish M, Obach RS, and Tremaine LM (2008) Prediction of drug-drug interactions from in vitro induction data: application of the relative induction score approach using cryopreserved human hepatocytes. Drug Metab Dispos 36:1971-1974.

Fahmi OA, Kish M, Boldt S, and Obach RS (2010) Cytochrome P450 3A4 mRNA is a more reliable marker than CYP3A4 activity for detecting pregnane $\mathrm{X}$ receptor-activated induction of drug-metabolizing enzymes. Drug Metab Dispos 38:1605-1611

Fahmi OA, Shebley M, Palamanda J, Sinz MW, Ramsden D, Einolf HJ, Chen L, and Wang H (2016) Evaluation of CYP2B6 Induction and Prediction of Clinical Drug-Drug Interactions: Considerations from the IQ Consortium Induction Working Group-An Industry Perspective. Drug Metab Dispos 44:1720-1730.

Fardel O and Le Vée M (2009) Regulation of human hepatic drug transporter expression by proinflammatory cytokines. Expert Opin Drug Metab Toxicol 5:1469-1481.

Farooq M, Kelly EJ, and Unadkat JD (2016) CYP2D6 Is Inducible by Endogenous and Exogenous Corticosteroids. Drug Metab Dispos 44:750-757.

Gerbal-Chaloin S, Pascussi JM, Pichard-Garcia L, Daujat M, Waechter F, Fabre JM, Carrère N, and Maurel P (2001) Induction of CYP2C genes in human hepatocytes in primary culture. Drug Metab Dispos 29:242-251.

Gerets HH, Tilmant K, Gerin B, Chanteux H, Depelchin BO, Dhalluin S, and Atienzar FA (2012) Characterization of primary human hepatocytes, HepG2 cells, and HepaRG cells at the mRNA level and CYP activity in response to inducers and their predictivity for the detection of human hepatotoxins. Cell Biol Toxicol 28:69-87.

Gibbons JA, de Vries M, Krauwinkel W, Ohtsu Y, Noukens J, van der Walt JS, Mol R, Mordenti J, and Ouatas T (2015) Pharmacokinetic drug interaction studies with enzalutamide. Clin Phar macokinet 54:1057-1069.

Godoy P, Hewitt NJ, Albrecht U, Andersen ME, Ansari N, Bhattacharya S, Bode JG, Bolleyn J, Borner C, Böttger J, et al. (2013) Recent advances in 2D and 3D in vitro systems using primary hepatocytes, alternative hepatocyte sources and non-parenchymal liver cells and their use in investigating mechanisms of hepatotoxicity, cell signaling and ADME. Arch Toxicol 87:1315-1530.

Grimm FA, Iwata Y, Sirenko O, Bittner M, and Rusyn I (2015) High-content assay multiplexing for toxicity screening in induced pluripotent stem cell-derived cardiomyocytes and hepatocytes. Assay Drug Dev Technol 13:529-546.

Guengerich FP, Shimada T, Iwasaki M, Butler MA, and Kadlubar FF (1990) Activation of carcinogens by human liver cytochromes P-450. Basic Life Sci 53:381-396.

Haertter S (2013) Recent examples on the clinical relevance of the CYP2D6 polymorphism and endogenous functionality of CYP2D6. Drug Metabol Drug Interact 28:209-216.

Hamilton GA, Jolley SL, Gilbert D, Coon DJ, Barros S, and LeCluyse EL (2001) Regulation of cel morphology and cytochrome P450 expression in human hepatocytes by extracellular matrix and cell-cell interactions. Cell Tissue Res 306:85-99.

Hariparsad N, Carr BA, Evers R, and Chu X (2008) Comparison of immortalized Fa2N-4 cells and human hepatocytes as in vitro models for cytochrome P450 induction. Drug Metab Dispos 36 $1046-1055$.

Healan-Greenberg C, Waring JF, Kempf DJ, Blomme EA, Tirona RG, and Kim RB (2008) A human immunodeficiency virus protease inhibitor is a novel functional inhibitor of human pregnane X receptor. Drug Metab Dispos 36:500-507.

Heimark LD, Gibaldi M, Trager WF, O'Reilly RA, and Goulart DA (1987) The mechanism of the warfarin-rifampin drug interaction in humans. Clin Pharmacol Ther 42:388-394.

Hewitt NJ, de Kanter R, and LeCluyse E (2007a) Induction of drug metabolizing enzymes: a survey of in vitro methodologies and interpretations used in the pharmaceutical industry-do they comply with FDA recommendations? Chem Biol Interact 168:51-65.

Hewitt NJ, Lechón MJ, Houston JB, Hallifax D, Brown HS, Maurel P, Kenna JG, Gustavsson L, Lohmann C, Skonberg C, et al. (2007b) Primary hepatocytes: current understanding of the regulation of metabolic enzymes and transporter proteins, and pharmaceutical practice for the use of hepatocytes in metabolism, enzyme induction, transporter, clearance, and hepatotoxicity studies. Drug Metab Rev 39:159-234.

Hewitt NJ, Lecluyse EL, and Ferguson SS (2007c) Induction of hepatic cytochrome P450 enzymes: methods, mechanisms, recommendations, and in vitro-in vivo correlations. Xenobiotica 37: 1196-1224.

Honkakoski P and Negishi M (2000) Regulation of cytochrome P450 (CYP) genes by nuclear receptors. Biochem J 347:321-337.

Huang SM, Zhao H, Lee JI, Reynolds K, Zhang L, Temple R, and Lesko LJ (2010) Therapeutic protein-drug interactions and implications for drug development. Clin Pharmacol Ther 87: 497-503.

Ingelman-Sundberg M (2005) Genetic polymorphisms of cytochrome P450 2D6 (CYP2D6): clinical consequences, evolutionary aspects and functional diversity. Pharmacogenomics $J \mathbf{5}$ $6-13$

Joshi P and Lee MY (2015) High content imaging (HCI) on miniaturized three-dimensional (3D) cell cultures. Biosensors (Basel) 5:768-790.

Kawamoto T, Sueyoshi T, Zelko I, Moore R, Washburn K, and Negishi M (1999) Phenobarbitalresponsive nuclear translocation of the receptor CAR in induction of the CYP2B gene. Mol Cell Biol 19:6318-6322.

Khetani SR and Bhatia SN (2008) Microscale culture of human liver cells for drug development. Nat Biotechnol 26:120-126.

Kirby BJ, Collier AC, Kharasch ED, Dixit V, Desai P, Whittington D, Thummel KE, and Unadkat JD (2011) Complex drug interactions of HIV protease inhibitors 2: in vivo induction and in vitro to in vivo correlation of induction of cytochrome P450 1A2, 2B6, and 2C9 by ritonavir or nelfinavir. Drug Metab Dispos 39:2329-2337.

Koh KH, Jurkovic S, Yang K, Choi SY, Jung JW, Kim KP, Zhang W, and Jeong H (2012) Estradiol induces cytochrome P450 2B6 expression at high concentrations: implication in estrogen-mediated gene regulation in pregnancy. Biochem Pharmacol 84:93-103.

Krause P, Saghatolislam F, Koenig S, Unthan-Fechner K, and Probst I (2009) Maintaining hepatocyte differentiation in vitro through co-culture with hepatic stellate cells. In Vitro Cell Dev Biol Anim 45:205-212.

Krausova L, Stejskalova L, Wang H, Vrzal R, Dvorak Z, Mani S, and Pavek P (2011) Metformin suppresses pregnane $\mathrm{X}$ receptor (PXR)-regulated transactivation of CYP3A4 gene. Biochem Pharmacol 82:1771-1780.

Kyrklund C, Backman JT, Kivistö KT, Neuvonen M, Laitila J, and Neuvonen PJ (2000) Rifampin greatly reduces plasma simvastatin and simvastatin acid concentrations. Clin Pharmacol Ther 68:592-597. 
Lauschke VM, Vorrink SU, Moro SM, Rezayee F, Nordling Å, Hendriks DF, Bell CC, SisonYoung R, Park BK, Goldring CE, et al. (2016) Massive rearrangements of cellular MicroRNA signatures are key drivers of hepatocyte dedifferentiation. Hepatology 64:1743-1756.

LeCluyse E, Madan A, Hamilton G, Carroll K, DeHaan R, and Parkinson A (2000) Expression and regulation of cytochrome $\mathrm{P} 450$ enzymes in primary cultures of human hepatocytes. J Biochem Mol Toxicol 14:177-188.

LeCluyse EL, Witek RP, Andersen ME, and Powers MJ (2012) Organotypic liver culture models: meeting current challenges in toxicity testing. Crit Rev Toxicol 42:501-548.

Lee JI, Zhang L, Men AY, Kenna LA, and Huang SM (2010) CYP-mediated therapeutic proteindrug interactions: clinical findings, proposed mechanisms and regulatory implications. Clin Pharmacokinet 49:295-310.

Li AP, Reith MK, Rasmussen A, Gorski JC, Hall SD, Xu L, Kaminski DL, and Cheng LK (1997) Primary human hepatocytes as a tool for the evaluation of structure-activity relationship in cytochrome P450 induction potential of xenobiotics: evaluation of rifampin, rifapentine and rifabutin. Chem Biol Interact 107:17-30.

Li W, Zhou J, and Xu Y (2015) Study of the in vitro cytotoxicity testing of medical devices. Biomed Rep 3:617-620.

Lim YP, Ma CY, Liu CL, Lin YH, Hu ML, Chen JJ, Hung DZ, Hsieh WT, and Huang JD (2012) Sesamin: a naturally occurring lignan inhibits CYP3A4 by antagonizing the pregnane $\mathrm{X}$ receptor activation. $e$ CAM 2012:242810.

Lin JH (2006) CYP induction-mediated drug interactions: in vitro assessment and clinical implications. Pharm Res 23:1089-1116.

Link B, Haschke M, Grignaschi N, Bodmer M, Aschmann YZ, Wenk M, and Krähenbühl S (2008) Pharmacokinetics of intravenous and oral midazolam in plasma and saliva in humans: usefulness of saliva as matrix for CYP3A phenotyping. Br J Clin Pharmacol 66:473-484.

Lu Y, Chen J, Xiao M, Li W, and Miller DD (2012) An overview of tubulin inhibitors that interact with the colchicine binding site. Pharm Res 29:2943-2971.

Mackowiak B and Wang H (2016) Mechanisms of xenobiotic receptor activation: direct vs. indirect. Biochim Biophys Acta 1859:1130-1140.

Maglich JM, Parks DJ, Moore LB, Collins JL, Goodwin B, Billin AN, Stoltz CA, Kliewer SA, Lambert MH, Willson TM, et al. (2003) Identification of a novel human constitutive androstane receptor (CAR) agonist and its use in the identification of CAR target genes. J Biol Chem 278 $17277-17283$

Makia NL and Goldstein JA (2016) CYP2C8 is a novel target of peroxisome proliferator-activated receptor $\alpha$ in human liver. Mol Pharmacol 89:154-164.

Michaud V, Ogburn E, Thong N, Aregbe AO, Quigg TC, Flockhart DA, and Desta Z (2012) Induction of CYP2C19 and CYP3A activity following repeated administration of efavirenz in healthy volunteers. Clin Pharmacol Ther 91:475-482.

Ministry of Health (MHLW) (2014) Drug Interaction Guideline for Drug Development and Labeling Recommendations (draft). Ministry of Health, Labour and Welfare, Japan.

Morcos PN, Chang L, Kulkarni R, Giraudon M, Shulman N, Brennan BJ, Smith PF, and Tran JQ (2013) A randomised study of the effect of danoprevir/ritonavir or ritonavir on substrates of cytochrome P450 (CYP) 3A and 2C9 in chronic hepatitis C patients using a drug cocktail. Eur Clin Pharmacol 69:1939-1949.

Pascussi JM, Drocourt L, Gerbal-Chaloin S, Fabre JM, Maurel P, and Vilarem MJ (2001) Dua effect of dexamethasone on CYP3A4 gene expression in human hepatocytes: sequential role of glucocorticoid receptor and pregnane X receptor. Eur J Biochem/FEBS 268:6346-6358.

Paul GA, Gibbs JS, Boobis AR, Abbas A, and Wilkins MR (2005) Bosentan decreases the plasma concentration of sildenafil when coprescribed in pulmonary hypertension. Br J Clin Pharmacol 60: $107-112$

Pichard-Garcia L, Gerbal-Chaloin S, Ferrini JB, Fabre JM, and Maurel P (2002) Use of long-term cultures of human hepatocytes to study cytochrome P450 gene expression. Methods Enzymol 357:311-321.

Prueksaritanont T, Vega JM, Zhao J, Gagliano K, Kuznetsova O, Musser B, Amin RD, Liu L, Roadcap BA, Dilzer S, et al. (2001) Interactions between simvastatin and troglitazone or pioglitazone in healthy subjects. $J$ Clin Pharmacol 41:573-581.

Ramsden D, Tweedie DJ, Chan TS, and Tracy TS (2014) Altered CYP2C9 activity following modulation of CYP3A4 levels in human hepatocytes: an example of protein-protein interactions. Drug Metab Dispos 42:1940-1946.

Ramsden D, Zhou J, and Tweedie DJ (2015) Determination of a degradation constant for CYP3A4 by direct suppression of mRNA in a novel human hepatocyte model, HepatoPac. Drug Metab Dispos 43:1307-1315.

Raucy JL, Mueller L, Duan K, Allen SW, Strom S, and Lasker JM (2002) Expression and induction of CYP2C P450 enzymes in primary cultures of human hepatocytes. J Pharmacol Exp Ther $\mathbf{3 0 2}$ $475-482$.

Riddick DS, Lee C, Bhathena A, Timsit YE, Cheng PY, Morgan ET, Prough RA, Ripp SL, Miller KK, Jahan A, et al. (2004) Transcriptional suppression of cytochrome P450 genes by endogenous and exogenous chemicals. Drug Metab Dispos 32:367-375.

Rodríguez-Antona C, Donato MT, Boobis A, Edwards RJ, Watts PS, Castell JV, and GómezLechón MJ (2002) Cytochrome P450 expression in human hepatocytes and hepatoma cell lines: molecular mechanisms that determine lower expression in cultured cells. Xenobiotica 32 505-520.

Runge D, Köhler C, Kostrubsky VE, Jäger D, Lehmann T, Runge DM, May U, Stolz DB, Strom SC, Fleig WE, et al. (2000) Induction of cytochrome P450 (CYP)1A1, CYP1A2, and CYP3A4 but not of $\mathrm{CYP} 2 \mathrm{C}$, CYP2C19, multidrug resistance (MDR-1) and multidrug resistance associated protein (MRP-1) by prototypical inducers in human hepatocytes. Biochem Biophys Res Commun 273:333-341.

Sager JE, Tripathy S, Price LS, Nath A, Chang J, Stephenson-Famy A, and Isoherranen N (2017) In vitro to in vivo extrapolation of the complex drug-drug interaction of bupropion and its metabolites with CYP2D6; simultaneous reversible inhibition and CYP2D6 downregulation. Biochem Pharmacol 123:85-96.

Sahi J, Shord SS, Lindley C, Ferguson S, and LeCluyse EL (2009) Regulation of cytochrome P450 2C9 expression in primary cultures of human hepatocytes. J Biochem Mol Toxicol 23:43-58.

Saliem M, Holm F, Tengzelius RB, Jorns C, Nilsson LM, Ericzon BG, Ellis E, and Hovatta O (2012) Improved cryopreservation of human hepatocytes using a new xeno free cryoprotectant solution. World J Hepatol 4:176-183.

Shadle CR, Lee Y, Majumdar AK, Petty KJ, Gargano C, Bradstreet TE, Evans JK, and Blum RA (2004) Evaluation of potential inductive effects of aprepitant on cytochrome P450 3A4 and 2C9 activity. J Clin Pharmacol 44:215-223.

Shang W, Liu J, Chen R, Ning R, Xiong J, Liu W, Mao Z, Hu G, and Yang J (2016) Fluoxetine reduces CES1, CES2, and CYP3A4 expression through decreasing PXR and increasing DEC1 in HepG2 cells. Xenobiotica 46:393-405.

Sinz M, Kim S, Zhu Z, Chen T, Anthony M, Dickinson K, and Rodrigues AD (2006) Evaluation of 170 xenobiotics as transactivators of human pregnane $\mathrm{X}$ receptor (hPXR) and correlation to known CYP3A4 drug interactions. Curr Drug Metab 7:375-388.

Soldatow VY, Lecluyse EL, Griffith LG, and Rusyn I (2013) In vitro models for liver toxicity testing. Toxicol Res (Camb) 2:23-39.

Subramanian M, Tam H, Zheng H, and Tracy TS (2010) CYP2C9-CYP3A4 protein-protein interactions: role of the hydrophobic N terminus. Drug Metab Dispos 38:1003-1009.

Synold TW, Dussault I, and Forman BM (2001) The orphan nuclear receptor SXR coordinately regulates drug metabolism and efflux. Nat Med 7:584-590.

Takeshita A, Taguchi M, Koibuchi N, and Ozawa Y (2002) Putative role of the orphan nuclear receptor SXR (steroid and xenobiotic receptor) in the mechanism of CYP3A4 inhibition by xenobiotics. J Biol Chem 277:32453-32458.

Teh LK and Bertilsson L (2012) Pharmacogenomics of CYP2D6: molecular genetics, interethnic differences and clinical importance. Drug Metab Pharmacokinet 27:55-67.

Ucar M, Neuvonen M, Luurila H, Dahlqvist R, Neuvonen PJ, and Mjörndal T (2004) Carbamazepine markedly reduces serum concentrations of simvastatin and simvastatin acid. Eur J Clin Pharmacol 59:879-882

Urquhart BL, Tirona RG, and Kim RB (2007) Nuclear receptors and the regulation of drugmetabolizing enzymes and drug transporters: implications for interindividual variability in response to drugs. J Clin Pharmacol 47:566-578.

Wang H and Negishi M (2003) Transcriptional regulation of cytochrome p450 2B genes by nuclear receptors. Curr Drug Metab 4:515-525.

Weber C, Banken L, Birnboeck H, and Schulz R (1999) Effect of the endothelin-receptor antagonist bosentan on the pharmacokinetics and pharmacodynamics of warfarin. $J$ Clin Pharmacol 39:847-854

Xu RX, Lambert MH, Wisely BB, Warren EN, Weinert EE, Waitt GM, Williams JD, Collins JL, Moore LB, Willson TM, et al. (2004) A structural basis for constitutive activity in the human CAR/RXRalpha heterodimer. Mol Cell 16:919-928.

Yajima K, Uno Y, Murayama N, Uehara S, Shimizu M, Nakamura C, Iwasaki K, Utoh M, and Yamazaki H (2014) Evaluation of 23 lots of commercially available cryopreserved hepatocytes for induction assays of human cytochromes P450. Drug Metab Dispos 42:867-871.

Yang H, Garzel B, Heyward S, Moeller T, Shapiro P, and Wang H (2014) Metformin represses drug-induced expression of CYP2B6 by modulating the constitutive androstane receptor signaling. Mol Pharmacol 85:249-260.

Yang K, Koh KH, and Jeong H (2010) Induction of CYP2B6 and CYP3A4 expression by 1-aminobenzotriazole (ABT) in human hepatocytes. Drug Metab Lett 4:129-133.

Yu D, Green B, Tolleson WH, Jin Y, Mei N, Guo Y, Deng H, Pogribny I, and Ning B (2015) MicroRNA hsa-miR-29a-3p modulates CYP2C19 in human liver cells. Biochem Pharmacol 98: 215-223.

Zamek-Gliszczynski MJ, Mohutsky MA, Rehmel JL, and Ke AB (2014) Investigational smallmolecule drug selectively suppresses constitutive CYP2B6 activity at the gene transcription level: physiologically based pharmacokinetic model assessment of clinical drug interaction risk Drug Metab Dispos 42:1008-1015.

Zhou C, Poulton EJ, Grün F, Bammler TK, Blumberg B, Thummel KE, and Eaton DL (2007) The dietary isothiocyanate sulforaphane is an antagonist of the human steroid and xenobiotic nuclear receptor. Mol Pharmacol 71:220-229.

Zilly W, Breimer DD, and Richter E (1975) Induction of drug metabolism in man after rifampicin treatment measured by increased hexobarbital and tolbutamide clearance. Eur J Clin Pharmacol 9:219-227.

Address correspondence to: Dr. Niresh Hariparsad, Department of Drug Metabolism and Pharmacokinetics, 4022 Vertex 1, 50 Northern Drive, Boston, MA 02210. E-mail: Niresh_hariparsad@vrtx.com 